\title{
A música demoníaca de Adrian Leverkühn como síntese da danação romântica da arte moderna
}

\author{
Maryson José Siqueira Borges ${ }^{1}$ \\ Mas se me tiras a voz - adisse a pequena sereia - que me restará? \\ (A pequena sereia, \\ Hans Christian Andersen)
}

\begin{abstract}
Zusammenfassung: Die zentrale Idee dieses Artikels ist es, die fundamentale Rolle einiger Aspekte des romantischen Denkens aufzuzeigen, die im Verständnis der Beziehung zwischen Künstler und Gesellschaft von Thomas Mann in seinem Roman Doktor Faustus kritisch exponiert werden. In dieser Perspektive wird erörtert, dass eine deformierende negative Überspannung der romantischen Tradition - auf die Weise, wie sie im Roman und in der Entwicklung des Protagonisten, des Musikers Adrian Leverkühn vorgestellt wird -, als Gemeinsamkeit zwischen der Beurteilung der sozialen Rolle des Künstlers durch Mann, dem hermetischen Charakter der modernen Ästhetik und der existentiellen und künstlerischen Dekadenz des Romanprotagonisten, ein entscheidender Aspekt für das Verständnis der Problematisierung der Beziehung zwischen Kunst und Gesellschaft, wie sie hier präsentiert wird, ist. Die Struktur des Artikels stellt das Verständnis der Relevanz dieses romantischen Einflusses in den Kontexten moderner Kunst ausgehend von drei verschiedenen und komplementären Sichtweisen vor. Genauer gesagt: die ästhetischen und politischen Betrachtungen des Intellektuellen Thomas Mann; die Beziehungen zwischen der Romantik und der Dissolution des tonalen Systems in der modernen Musik und, schließlich, der sterile und stumme Intellektualismus der Kunst von Leverkühn. Die Idee dieser Aufteilung ist es demnach anhand der sozio-politischen Dimension der kritischen Reflexion (Selbstbetrachtung des Autors) und anhand der ästhetischen Dimension (die Transformationen innerhalb des tonalen Systems der klassischen Musik) die zwei fundamentalen Elemente zu betrachten, die den Roman strukturieren und so das kritische Vermögen der literarischen Elaboration solcher Fragen stärker zu beleuchten.
\end{abstract}

Stichwörter: Romantik; Kunst; Musik; Gesellschaft; Politik; Kritik

\footnotetext{
${ }^{1}$ Doutor em Teoria e Crítica Literária pela FCLAr/UNESP, professor do programa de Pós-graduação em Letras da Universidade Federal da Paraíba e coordenador do projeto "Fundamentos e contribuições crítico-teóricas do pensamento estético de Walter Benjamin", financiado pelo CNPq e pela Fundação de Amparo à Pesquisa da Paraíba. E-mail: marysonborges@ gmail.com
} 
Borges, M. J. S. - A música demoníaca de Adrian Leverkühn

\begin{abstract}
The central idea of this article is to point at the fundamental role of some aspects of the romantic intellectual tradition for the understanding of the relation between the artist and society critically exposed by Thomas Mann in his novel Doktor Faustus. In this perspective, it is considered that an exacerbation deforming the romantic tradition is - in the ways this is suggested in the novel and in the trajectory of the protagonist, the musician Adrian Leverkühn a common point between Mann's evaluation of the social role of the artist, the hermetic character of modern aesthetics and of an existential and artistic decadence of the novel's protagonist, a decisive aspect for the understanding of the problematic relation between art and society here presented. The structure of the article proposes the understanding of the relevance of this romantic influence in modern art from the viewpoint of three different and complementary angles, i.e. the aesthetic and political considerations of the intellectual Thomas Mann; the relations between romanticism and the dissolution of the tonal system in modern music and, finally, the sterile and mute intellectualism of Leverkühn's art. The idea of this division is hence the contemplation of two fundamental elements that structure the novel by passing through the socio-political dimension of critical reflection (self-analysis of the author) and the aesthetical dimension (the transformations within the tonal system of erudite music) and, from this perspective, the article seeks to elucidate the critical proposal of a literary elaboration of such questions.
\end{abstract}

Keywords: Romanticism; art; music; society; politics; criticism

Resumo: A idéia central deste artigo é apontar o papel fundamental de alguns aspectos do pensamento romântico na compreensão da relação entre artista e sociedade, exposta criticamente por Thomas Mann em seu romance Doktor Faustus. Nessa perspectiva, considerase que uma exacerbação deformadora da tradição romântica - nos moldes em que ela é sugerida no romance e na trajetória do protagonista, o músico Adrian Leverkühn - é, enquanto ponto em comum da avaliação de Mann sobre o papel social do artista, sobre o caráter hermético da estética moderna e a decadência existencial e artística do protagonista do romance, um aspecto decisivo para entendimento da problematização da relação entre arte e sociedade ali apresentada. A estrutura do artigo propõe o entendimento da relevância desta influência romântica nos rumos da arte moderna a partir de três ângulos distintos e complementares. Nomeadamente: as considerações estéticas e políticas do intelectual Thomas Mann; as relações entre o Romantismo e a dissolução do sistema tonal na música moderna e, por fim, o intelectualismo estéril e mudo da arte de Leverkühn. A idéia desta divisão é, pois, passando pela dimensão sócio-política da reflexão crítica (auto-avaliação do autor) e pela dimensão estética (as transformações dentro do sistema tonal da música erudita), contemplar os dois elementos fundamentais que estruturam o romance e vislumbrar mais nitidamente a proposição crítica da elaboração literária de tais questões.

Palavras-chave: Romantismo; arte; música; sociedade; política; crítica. 
Borges, M. J. S. - A música demoníaca de Adrian Leverkühn

\section{O lugar do Doktor Faustus na poética de Mann}

Muitos críticos são categóricos ao classificar o Doktor Faustus como o ápice das preocupações estéticas, morais e sociais de Thomas Mann e, por tal razão, como uma espécie de síntese do projeto literário que foi a própria vida do autor. Em favor desse argumento pesa o fato de Mann não ter sido um escritor de uma só grande obra. Ele foi, na verdade, o autor de uma só grande poética. Os seus textos possuem entre si elos, visíveis ou tácitos, que conferem à óbvia paternidade autoral de cada um, senão uma unidade temática profunda, pelo menos uma coerente e reiterada retomada de aspectos que se afiguravam como fundamentais para um pensador tão voltado para o seu tempo.

Dentre alguns destes aspectos que constituem a poética manniana, a questão da condição e do papel do artista na sociedade moderna possui relevância destacada. Grande parte de sua obra foi, pois, marcada pela reflexão sobre o instável contraponto entre o ideal estético-utópico herdado do movimento romântico e da sociedade burguesa e a premente responsabilidade histórica que se impõe à praxis social do artista moderno. Anatol Rosenfeld chama a atenção para esta recorrente preocupação do autor com a busca do equilíbrio entre os elementos que, num âmbito mais particular, restrito, forjam a sua postura de intelectual e de artista, e que, por conseguinte, num sentido mais amplo, dizem respeito à própria identidade do povo alemão, outra preocupação constante do escritor:

Toda a vida de Thomas Mann, no seu sentido mais profundo, é um constante esforço de superar a sua natureza, impregnado do romantismo musical da Alemanha, a sua vida é uma vida exemplar no seu aspecto de superação moral e de vitória sobre as suas mais profundas inclinações. E toda a sua vida nada é senão a expressão estética desse esforço de contrapor os dois valores, de pô-los em xeque, de referi-los num jogo de dialética altamente ambígua, de ironizarlhes a unilateralidade, de salientar a necessidade de sua síntese final num humanismo em que espírito e vida se interpenetrem e em que o indivíduo isolado se integre de novo na sociedade, enriquecido pela experiência da "doença", da "morte" e da alienação. (RosENFELD 1994: 93)

Para Mann, esses dois valores determinantes e conflitantes - a praktische Vernunft, para usar um termo kantiano, e o isolamento estético de espírito romântico são os pólos extremos da propensão do artista moderno, e na inclinação excessiva para 
Borges, M. J. S. - A música demoníaca de Adrian Leverkühn

um dos lados, especialmente o estético-utópico, é que reside a danação da arte de seu tempo. Por tal razão, como atesta Rosenfeld no trecho acima exposto, a busca de uma posição eqüidistante entre estes dois mundos foi o que norteou a vida e a produção literária de Mann.

Tomado nesse sentido, Doktor Faustus foi, de fato, no opúsculo de Mann, um momento culminante no embate das duas forças espirituais que constituem a filosofia de sua poética. Isso se reforça de maneira ainda mais contundente se se considera que neste romance, pois, o ápice das preocupações estéticas do autor coincide com o agravamento de uma crise política que desembocará no nazismo e consolidará ainda mais suas convicções estético-filosóficas.

Enquanto escreve o seu Fausto, amadurecido pelo exílio nos Estados Unidos e pela observação estarrecida da decadência moral de seu país transpassado por duas guerras mundiais, Mann sinaliza em diversos momentos, por meio de discursos, conferências e cartas pessoais, com uma reflexão dura e bastante crítica sobre a responsabilidade dos intelectuais e do povo alemão no desenvolvimento da catástrofe humana e social que se abatera sobre aquele país e sobre a Europa. Numa espécie de mea culpa, o escritor que fôra um apolítico entusiasta do individualismo-nacionalista nos idos da Primeira Grande Guerra, revela nesta severa autocrítica o misticismo que envolvera seu ideal de nação espiritual e conclama o povo alemão a entregar-se ao amor e ser amado para que possa ser resgatado nesse povo o sentido de coletividade perdido em nome da distorcida introspecção romântica a que se dedicou o país:

Na timidez da alma alemã ante o mundo havia sempre tanto anseio do mundo; no fundo da sua solidão que a tornou má, jaz - quem não o saberia - o desejo de amar, o desejo de ser amada. A Alemanha, caso expulse orgulho e ódio de seu sangue, redescubra o amor e será amada...(RosENFELD 1994: 141)

Quando projeta, então, para a nação alemã a possibilidade "ser amada", Thomas Mann projeta a instauração de um novo ideal de sociedade, no qual o equilíbrio entre forças místicas (Romantismo) e racionais (Iluminismo) resulte numa civilização guiada pela luz de um sentido social mais humanístico e igualitário. Mann analisa, pois, o desequilíbrio entre estes dois vetores na Alemanha, amparado pela compreensão de que a construção da identidade desse país, devido ao anseio de unidade cultural e política e pela singular condição imperialista que durante anos emperrou possíveis relações

Pandaemonium germanicum 15/2010.1, p. 70-90 - www.fflch.usp.br/dlm/alemao/pandaemoniumgermanicum 
Borges, M. J. S. - A música demoníaca de Adrian Leverkühn

democráticas com outras nações da Europa, está pontuada ao longo dos séculos por significativa valorização de aspectos individuais e exclusivistas, como atestam, por exemplo, dois dos principais momentos da formação cultural do país: a reforma religiosa de Lutero e a revolução romântica. Nas origens destes dois momentos culturais pode-se inferir a propensão inata à evasão e ao isolamento que influenciou sensivelmente a constituição do povo alemão

No primeiro evento, como explica o próprio Mann, já podem ser pressentidos os indícios do orgulho defensivo e auto-suficiente de uma nação que se sabe amorfa e estranha à realidade dos países desenvolvidos no continente:

Lutero era um herói libertador, mas em estilo alemão. Nada sabia de liberdade. Não falo de liberdade do cristão, mas da liberdade política do cidadão, liberdade esta que não só deixava Lutero indiferente, mas cujas exigências lhe eram repugnantes... A concepção alemã da liberdade era sempre dirigida contra $\mathrm{o}$ exterior; ela acentuava apenas o direito de ser alemão, só alemão e nada além disto... é uma concepção de protesto apenas, de autodefesa contra tudo que tende a limitar e restringir o egoísmo nacional (ROSENFELD 1994: 140)

Num momento posterior, com o Romantismo, o mais alemão dos movimentos culturais modernos, esta condição de alheamento será ratificada definitivamente e transformada em solução utópica:

In der Qual der Erde wurzelt die Romantik, und so wird man ein Volk um so romantischer und elegischer finden, je unseliger sein Zustand ist" (...) Die Deutschen waren wohl das unseligste Volk in Europa (...) Das Gefühl der Heimatlosigkeit und der Vereinsamung wurde zum entscheidenden Erlebnis der neuen Generation; ihre ganze Weltanschauung war und blieb davon abhängig. Es nahm unzählige Formen an und fand seinen Ausdruck in einer Reihe von Fluchtversuchen, von welchen die Wendung zur Vergangenheit nur die ausgeprägteste war. (HAUSER 1990, 35)

$\mathrm{Na}$ perspectiva apontada por Hauser, a insatisfação com o presente e a incapacidade de transformação da realidade social é apresentada no Romantismo como fator propulsor da fuga para a utopia, para outros mundos, para a interioridade confortadora. Por isso, num só tempo, cumpre a ele ser na Alemanha tanto o amálgama da identidade de uma nação carente de unidade espiritual quanto emancipação da singularidade sócio-cultural de seus intelectuais. 
Borges, M. J. S. - A música demoníaca de Adrian Leverkühn

Para Mann, no entanto, a despeito da contribuição cultural advinda deste caráter do povo alemão, este mesmo apego à interioridade e à fuga utópica, que num primeiro instante deu sentido e unidade cultural à Alemanha, condenou seu povo a um grau de solidão e egoísmo nacional que culminaria num egocentrismo xenófobo estimulado ulteriormente pelo nazismo. Naturalmente, o escritor não estabelece com isso uma compreensão determinista do desenvolvimento da história. Sua autoreflexão, voltada para o destino que se cumpre neste país, pondera sobre a responsabilidade dos intelectuais que, embriagados pela ostentação de um germanismo chauvinista, fizeramse alheios à manipulação política desta perniciosa germanidade no caótico retrocesso social que grassou por toda Alemanha e Europa nos séculos XIX e XX. Mann engendra nesta revisão crítica sobre a interioridade da sua nação, uma reflexão sobre a parcela de culpa da classe artística alemã que, imersa na apática interioridade estética, mostrou-se incapaz de se desvencilhar da natureza omissa de sua condição romântico-burguesa para participar ativamente das questões mais práticas da vida social do país e intervir, por exemplo, na exacerbação capciosa dos anseios político-econômicos ultranacionalistas oportunamente defendidos por Hitler.

Como artista, Mann toma a iniciativa de condenar a si próprio pelo apartamento entre o mundo social e o mundo estético que se estabelecera na vida moderna. Por este motivo, se mais do que nunca a sua busca pelo equilíbrio entre a razão prática e a divagação romântica ganha sentido, nada mais justo que outorgar ao seu Doktor Faustus o papel de súmula crítica deste estágio estético e histórico da sua obra. O resultado dessa síntese é um romance soberbo. Seu grande mérito é o de ser a mimese de um momento fundamental da história contemporânea; ser a representação artística da problemática da cultura moderna e dos desdobramentos desta crise.

A inter-relação entre a subjetividade da criação estético-literária e a objetividade dos imperativos sociais e históricos que fomentou a reflexão político-filosófica de Mann é transformada na estrutura do Doktor Faustus em vozes que dialogam, ora em consonância, ora em desalinho, como se procurassem ao mesmo tempo se mesclar e se definir singularmente. O autor compõe, como Lukács já o dissera, uma "grande sinfonia", na qual, polifonicamente, melodias se interpenetram e se expelem para dar sentido a um todo musical mais complexo e completo. As duas linhas melódicas que se sobressaem neste discurso são exatamente representativas dos dois pólos extremos da poética manniana: o estético, expresso nas filigranas da criação artística do protagonista,

Pandaemonium germanicum 15/2010.1, p. 70-90 - www.fflch.usp.br/dlm/alemao/pandaemoniumgermanicum 


\section{Borges, M. J. S. - A música demoníaca de Adrian Leverkühn}

Adrian Leverkühn; e o histórico-social, registrado na relação da expansão nazista com esta crise da arte moderna.

O resultado desse diálogo sinfônico é a reflexão crítica sobre as origens românticas da trágica e singular adequação histórica alemã ao desenvolvimento da crise de valores sociais e estéticos que aflige o país. Segundo Mann, esta determinante presença romântica na alma alemã, como uma espécie de eco intermitente da índole subjetivista desta nação, se traduzirá, na crise estética da arte moderna, em música dodecafônica e, na crise sócio-política da República de Weimar, no nacionalsocialismo. Claro que não se trata de associar a questão romântica de maneira determinista nem ao nazismo nem à música serial. O que Mann concebe como o ônus romântico no desenvolvimento destes eventos é o fato de ele ser para a Alemanha ainda o grande catalisador, a expressão fiel e contundente, de uma série de valores subjetivistas e interiorizantes que dizem respeito ao caráter e anseio introspectivo de sua burguesia, mas que pouco contribuem para a necessidade de integração social mútua desta nação com os outros países da Europa e para a instauração nela de uma coletividade mais humanista. Mann critica, por isso, o pacto de conveniências fundado sobre a manipulação anacrônica de alguns destes valores românticos. Segundo sua concepção, neste pacto, a classe política, ao se apoderar do sentido místico-nacionalista da atitude romântica, afere ao fascismo emancipatório do anti-semitismo nazista a historicidade justificadora de seu isolamento e de suas ações imperialistas, enquanto os artistas e os intelectuais, inebriados pelo orgulho romântico do germanismo que se exalta, abrem mão de uma reflexão crítica mais aguda, numa resignação muda diante do caos social que se anuncia, em nome de uma estada tranqüila no mundo etéreo e ideal das elucubrações estéticas e filosóficas.

Der Rückzug in die „kleine Welt“ der Studierstube war für die beste Intelligenz erzwungen. Denn die objektiv-gesellschaftliche, primäre Erscheinungsweise der Krise des bürgerlichen Humanismus, die Krise der aus den großen Revolutionen hervorgegangenen bürgerlichen Demokratien, besteht gerade darin, daß jene Ideale, die von Rabelais bis Robespierre die großen öffentlichen - zugleich politischen und sozialen, kulturellen und künstlerischen - Angelegenheiten der progressiven Menschheitsentwicklung waren, ihren Zusammenhang mit den großen Zeitkämpfen, ihre vorwärtstreibende Wirksamkeit auf diese verlieren, daß sie zu Fortschrittshemmungen, $\mathrm{zu}$ ideologischen Waffen der konservatorischen Heuchelei werden. Die kulturschaffende Intelligenz ist aus 
Borges, M. J. S. - A música demoníaca de Adrian Leverkühn

dieser Lage in die „kleine Welt“ der Studierstube geflüchtet. Diese Flucht hatte ursprünglich den Sinn, die Reinheit der in den neugearteten Kämpfen immer mehr besudelten Ideale zu retten. Sie war ihren subjektiven Zielsetzungen nach eine Opposition. Je stärker jedoch die „kleine Welt“ sich um die Intelligenz zusammenschloß, je stärker sie in dieser hermetischeren Abgeschlossenheit ihre ausschließliche Lebenswirklichkeit wurde, desto stärker wirkten unterirdisch die reaktionären Tendenzen der kapitalistischen Welt auf die Problemstellungen und -lösungen dieser Intelligenz ein, auf Gehalt und Form ihrer scheinbar rein innerlich gewordenen Tätigkeit. Diese unterirdische Beeinflussung ist auch für sie nicht völlig unbewußt geblieben. Sie mußte jedoch in einer solchen Atmosphäre eine verzerrende Brechung erhalten: der Kult des Unbewußten, die Tiefenpsychologie, die Mythisierung des Innenlebens usw. sind in allen ihren verschiedenen weltanschaulichen und künstlerischen Formen Erscheinungsweisen dieser Selbstverzerrung der Innenwelt.

(LUKÁCS 1964: 578)

O crítico húngaro Georg Lukács ilustra nesse trecho, de maneira precisa, a evolução histórica da alienação social que foi a tônica entre os artistas românticos e que teve talvez na Alemanha sua reprodução mais exacerbada. Ele sintetiza aqui a progressiva obsolescência do sentido social da criação artística e a caminhada desta arte moderna rumo à autodissolução. Seu argumento endossa o sintomático fato de, no romance de Mann, a reflexão crítica sobre as implicações históricas do pacto que medra sorrateiramente na Alemanha de Weimar partir da representação de um compositor de uma música tão visceralmente hermética - a música dodecafônica ou serial. Lukács demonstra que Mann habilmente desenvolve esta associação tomando a questão estética como epicentro do enredo para prosseguir num diálogo crescente rumo a considerações mais amplas sobre a questão política. Com isso, naturalmente, Mann não visa subentender que historicamente a segunda questão decorre da primeira. Como atesta o tecido polifônico criado pelo autor para exprimir cada uma das vozes cunhadas na narração, seu intento não é meramente representar o desenvolvimento do processo histórico, mas sim propor um exercício crítico calcado exatamente no sentido dialético da relação entre história e arte. Doktor Faustus, como mimetização desta dialética, possui a coerente proposta de atrelar os atores da crise estética e política que se estabelece na Alemanha, dando-lhes a dimensão justa de sua responsabilidade histórica. Por isso, como não poderia ser diferente, não é a associação direta entre o nazismo e a música dodecafônica quem fomenta o entendimento do pensamento de Mann, mas sim a 
Borges, M. J. S. - A música demoníaca de Adrian Leverkühn

compreensão da presença sempre determinante do problema da interioridade romântica na formação do povo alemão e, por conseguinte, dos dois eventos.

\section{Origens românticas da música dodecafônica}

Analisando a presença desta música serial no romance se percebe a coerência da crítica de Mann na vinculação do destino trágico do protagonista ao subjetivismo romântico. O dodecafonismo possui laços hereditários que o associam diretamente à música romântica e à hermética interiorização estética do século XX.

Seguindo a linha evolutiva da música erudita ocidental, tem-se Beethoven como o grande expoente do último período clássico. Pelas condições históricas que preparam a emancipação da classe burguesa e pelo esgotamento da forma-sonata, expressão mais perfeita do sistema musical clássico, o período final de sua obra é marcado pela necessidade de expansão estrutural e intensificação do subjetivismo estético. Ela é, pois, a fresta pela qual a música romântica irá aos poucos emergir. Mais do que isso, a música tardia de Beethoven é o diagnóstico irreversível da derrisão do mundo tonal.

A lógica do discurso tonal é resolutiva. De maneira simplificada, pode-se dizer que a construção sintático-semântica do tonalismo está baseada num princípio harmônico que parte de um estado de repouso, segue em direção à tensão das dissonâncias harmônicas para, no limiar desta suspensão, voltar ao repouso conciliatório da consonância. Este esquema está, além de na macroestrutura da música tonal, na organização das partes que constituem a forma musical clássica por excelência: a sonata. Nela, a seqüência discursiva exposição-desenvolvimento-reexposição, obedece não só a necessidade de resolução das tensões, como também dá sentido ao exercício melódico dos temas e motivos da microestrutura das peças:

[...] podemos perceber o arco da sonata como uma amplificação, elevada ao nível da forma, daquilo que a cadência tonal realiza no nível da frase: repousotensão-repouso. Modulando e simetrizando, articulando os menores elementos na perspectiva do grande conjunto, encontrando passagens e mediações que conduzem os motivos entre si e os conduzam ao desígnio geral da obra, a sonata está realizando um traço da própria idéia ocidental de arte na sua versão clássica: a integração exaustiva das partes ao todo, portadas aqui pelas novas possibilidades abertas pela tonalidade em música, que permite um 
Borges, M. J. S. - A música demoníaca de Adrian Leverkühn

encadeamento cerrado e progressivo de materiais diferentes. (WISNIK 1989: 152)

Como se vê, o imperativo estético da lógica tonal clássica é o da estabilidade harmônica e estrutural e, portanto, da necessidade resolutiva. Em determinado grau, ele é também a expressão musical de um mundo clássico que ainda permite a crença no equilíbrio das partes num todo conciliador.

Contudo, como foi exposto acima, este paradigma estético que permanece em vigor na música erudita pelo menos até a derradeira fase criativa de Beethoven, perde o seu sentido histórico-filosófico quando às reverberações da ascensão e consolidação burguesa e ao movimento romântico juntam-se as necessidades de subjetivação musical e a consciência do esgotamento da forma-sonata e da lógica resolutiva do compositor de Bonn:

[...] à maneira dos quartetos finais de Beethoven, insinua-se já sobre a lógica das resoluções tonais a exposição da falha sobre a qual elas trabalham, o ponto onde rateia a máquina resolutiva (e o estado positivo da dialética). Prefigura-se a impossibilidade que o tonalismo encontrará, no seu devir, de reverter toda dissonância à resolução harmônica, e todo conflito à imagem de ordem apaziguada. Nesse lugar crucial da sua obra tardia, que já foi equiparada ao Goethe do último Fausto, no derradeiro movimento, do derradeiro quarteto, Beethoven inscreve a epígrafe poético-musical que se faz acompanhar de um motivo melódico espelhado: "É preciso? É preciso." (WISNIK 1989: 147)

Os sucedâneos formais que irão exaurir o período clássico na música serão endossados pela expansão do Romantismo na adoção semântica de experimentalismos subjetivistas e utópicos-sentimentais e no desenvolvimento sintático da progressão harmônica rumo à consolidação definitiva de modulações cromáticas que desembocarão no atonalismo do século XX. Entres os vários nomes representativos deste movimento como, Schubert, Schumann, Liszt, Chopin, Brahms, se sobressai o de Richard Wagner. A ele caberá a condução do sistema tonal aos limites da dissonância harmônica e a possível superação do romantismo musical:

No Tristão e Isolda (terminado em 1859), Wagner leva o sistema tonal, surgido nos século XVII, à beira da dissolução. O cromatismo do Tristão transforma-seá, no século $\mathrm{XX}$, em atonalismo e, posteriormente, em dodecafonismo. Esteticamente a obra representa também a dissolução mais radical de qualquer 
Borges, M. J. S. - A música demoníaca de Adrian Leverkühn

forma de estrutura emocional ou musical. É um estar-à-mercê de vagalhões informes de sentimentos e desejos. A postura de Wagner é pessimista como a de Schopenhauer: “... redenção das antinomias do ser pela negação da vontade de viver.” (KIEFER 2002: 230)

Assim como a música de Beethoven já cumprira o papel de preparadora do desenvolvimento da música romântica subseqüente, Wagner esboça, com o cromatismo extremo de seu drama musical, o caos que se abaterá sobre o combalido tonalismo do século XIX. No entanto, contrariamente ao que sucedera a Beethoven, o que o poeta de Bayreuth inaugura com a Gesamtkunstwerk e sua clara propensão romântica de retorno ao nacionalismo mitológico, não condiz no âmbito histórico com o anseio críticoreflexivo de seu tempo. Figura controversa, Wagner marcha na direção de um pessimismo extremo e proclama neste pendor romântico o culto anacrônico do passado e da morte. Encontra-se, pois, alheio à crise dos valores humanistas que inexoravelmente se espraia pela Europa, priorizando o caráter estético-utópico da obra de arte em detrimento da capacidade transformadora e auto-suficiente do Übermensch de Nietzsche.

Num pequeno discurso chamado Rede, gehalten zur Feier des 80. Geburtstages Friedrich Nietzsches, escrito ainda em 1924, Mann reflete sobre a questão e parece inclinado a aliar-se a Nietzsche na compreensão de que, ao optar pelo cristianismo no Parsifal e reverenciar elementos musicais de um romantismo caduco, Wagner trai a necessidade revolucionária de se criar uma arte pós-romântica voltada para a sagração da vida, para a auto-superação:

Daß aber Wagner ein mächtig-glückhafter Selbstverherrlicher und Selbstvollender, Nietzsche dagegen ein revolutionärer Selbstüberwinder war, das macht es, daß jener auch nur der letzte Verherrlicher und unendlich bezaubernde Vollender einer Epoche blieb, dieser aber zu einem Seher und Führer in neue Menschenzukunft geworden ist.

e complementa:

Dies ist er uns: ein Freund des Lebens, ein Seher höheren Menschentums, ein Führer in die Zukunft, ein Lehrer der Überwindung all dessen in uns, was dem Leben und der Zukunft entgegensteht, das heißt des Romantischen. Denn das Romantische ist das Lied des Heimwehs nach dem Vergangenen, das Zauberlied des Todes; und das Phänomen Richard Wagners, das Nietzsche so 
Borges, M. J. S. - A música demoníaca de Adrian Leverkühn

unendlich geliebt hat und das sein regierender Geist überwinden mußte, war kein anderes, als das paradoxe und ewig fesselnde Phänomen welterobernder Todestrunkenheit. (MANN 1925)

Este é o ponto crucial da escolha de Mann. Em sintonia com Nietzsche, ele concebe que Wagner como expoente do Romantismo musical não foi capaz ou não quis superar estes valores que, por estarem voltados para o passado e para um esteticismo extremo, traziam consigo os germes da destruição da vida. Nietzsche assevera:

Jede wahrhafte, jede originale Musik ist Schwanengesang. - Vielleicht, dass auch unsre letze Musik, so sehr sie herrscht und herrschsüchtig ist, bloss noch eine kurze Spanne Zeit vor sich hat: denn sie entsprang einer Cultur, deren Boden im raschen Absinken begriffen ist, - einer alsbald versunkenen Cultur. Ein gewisser Katholicismus des Gefühls und eine Lust an irgend welchen altheimischen sogenannten „nationalen“ Wesen und Unwesen sind ihre Voraussetzungen. Wagner's Aneignung alter Sagen und Lieder, in denen das gelehrte Vorurtheil etwas Germanisches par excellence zu sehn gelehrt hatte heute lachen wir darüber -, die Neubeseelung dieser skandinavischen Unthiere mit einem Durst nach verzückter Sinnlichkeit und Entsinnlichung - dieses ganze Nehmen und Geben Wagner's in Hinsicht auf Stoffe, Gestalten, Leidenschaften und Nerven spricht deutlich auch den Geist seiner Musik aus, gesetzt dass diese selbst, wie jede Musik, nicht unzweideutig von sich zu reden wüsste (...) Das Zeitalter der nationalen Kriege, des ultramontanen Martyriums, diese ganze Zwischenakts-Charakter, der den Züstanden Europas's jetzt eignet, mag in der That einer solchen Kunst, wie Wagner's, zu einer plötzlichen Glorie verhelfen, ohne ihr damit Zukunft zu bürgen. Die Deutschen selber haben keine Zukunft... (NIETZSCHE 1906: 191)

Cabe, diante desta ácida crítica de Nietzsche ao sentido da música wagneriana, um pequeno parêntese para ressaltar que, a despeito dessa "escolha" romântica, a contribuição de Wagner, no que concerne à dissolução do sistema tonal, não pode jamais ser negada ou negligenciada na história da música ocidental, haja vista que é a partir da continuidade do cromatismo wagneriano que, ulteriormente, sedimenta-se o terreno - já preparado por compositores como Berlioz e Mahler - sob o qual Schönberg fará germinar sua teoria dodecafônica A arte de Wagner é a grande revolução musical que desembocará no atonalismo.

A música do século XX, sobretudo na especulação teórica de Schönberg, é assim a expansão de uma série de transformações estéticas em curso no século XIX, grosso modo catalisadas na dissolução tonal wagneriana. Contudo, apesar deste determinante parentesco técnico-teórico, em pelo menos um aspecto fundamental a música 


\section{Borges, M. J. S. - A música demoníaca de Adrian Leverkühn}

schönbergiana segue um caminho oposto ao da de Wagner: o do primado da mimesehistórica na criação artística. Neste sentido, mais do que simplesmente extenuar a dissolução do sistema tonal num incessante exercício de modulações cromáticas, Arnold Schönberg restaura o mimetismo histórico subestimado por Wagner. Ela dá uma espécie de continuidade dialética ao esteticismo hermético dos românticos, mas, de maneira diversa ao que ocorrera com Wagner, neste hermetismo a mimese contextual que se impõe ao pensamento dodecafônico o investe de um sentido crítico que o drama musical das óperas de Bayreuth prescindia.

Por tal razão, muito mais do que ser fruto de um imperativo meramente formal, de ser o prosseguimento da evolução e aniquilamento da música tonal, o dodecafonismo ou serialismo de Schönberg é, com efeito, a mimese musical dos imperativos do século que se inicia. Noutras palavras, na passagem da música de Wagner para a música de Schönberg, sem esquecer a gama de compositores que se insere entre eles e suas respectivas contribuições, se dará uma paradoxal bifurcação do desenvolvimento estético-filosófico da grande música do ocidente. Wagner, como já foi exposto, conduz o sistema tonal à sua aniquilação, conquanto este esgotamento não se consume. Schönberg, herdeiro inconteste desta evolução teórica, irá prosseguir com a dissolução do sistema tonal, num sentido oposto a Wagner, propondo o dodecafonismo atonal como resposta dialética. Mais do que isso, esta oposição é quem dará sentido filosófico para a função progressista desta nova música. Nestes termos, entendendo Wagner como último grande compositor do período romântico, o parentesco do serialismo com o Romantismo se dará num movimento duplo: como continuidade histórica, no âmbito da lógica tonal, e como negação crítica de seu mimetismo anacrônico. Impõe-se assim, dialeticamente, ao "alienado" culto à estética e aos valores românticos de Wagner, uma nova forma de arte hermética que nega as condições histórico-materiais da sociedade moderna ao afirmar seu imperativo crítico.

\section{A dialética da consciência tardia de Leverkühn}

Schönberg escreve, portanto, a música que representa o diagnóstico da arte do século XX. Ela materializa o estágio em que se encontra a relação da arte com esta sociedade atomizada e de consumo. Muito esclarecedor desta questão é o interessante 
Borges, M. J. S. - A música demoníaca de Adrian Leverkühn

capítulo sobre música serial, incluso no livro $O$ som e o sentido, no qual, José Miguel

Wisnik comenta a concepção crítica da música de Schönberg defendida por Adorno:

Schönberg é, para o pensador neo-hegeliano -, o artista dialético por excelência, que assume o estado atual da linguagem em toda a extensão de suas contradições. O compositor austríaco leva, segundo ele (Adorno), às últimas consequiências lógicas a própria história da música alemã, vale dizer da tonalidade como drama. Schönberg teria encarado a impossibilidade de compor autenticamente uma música consoladora e afirmativa numa sociedade cuja divisão coisificadora é um dissolvente de toda harmonia. Seu maior valor estaria em prosseguir, sob a égide da atonalidade, e portanto da negação, aquela busca de coerência de todos os elementos que deriva da melhor tradição beethoveniana e brahmsiana. Nessa dialética negativa, o melhor modo de corresponder à grande tradição tonal alemã (que permanece para Adorno como grande modelo) seria através de uma música atonal, que libera a dissonância como algo mais racional que a consonância, pois exibe de maneira articulada a relação heterogênea dos sons nela presentes. (Nesse sentido, já se vê que a consonância, onde se figura uma unidade sonora aparentemente homogênea, adquire historicamente para Adorno o caráter de ideologia, no sentido marxista de "falsa consciência)." (WISNIK 1989: 187)

Ao dar continuidade a sua explanação, o autor irá, além de definir o caráter progressista atribuído por Adorno à música de Schönberg, aproximar sugestivamente a figura do crítico musical do autor do Doktor Faustus, Thomas Mann:

(...) Assumindo sofridamente a necessidade de um sistema que é contraditoriamente recusa e reflexo imposto da ordem existente, sistema que ela funda e contesta, a música de Schönberg participaria, segundo Adorno, de uma racionalidade dialética. (...) Thomas Mann e Adorno olham, portanto, de dentro ou do alto da tradição alemã, para a profunda ambivalência da música dodecafônica (e para a desolação de todo o resto). Essa ambivalência de traduz em Mann, numa ironia essencial (se se pode assim dizer), e em Adorno numa dialética agônica que afirma um progresso que não tem como progredir, e que é a própria expressão do fim do ciclo tonal, com cuja história o pensamento dialético, pelo menos tal como Adorno o pratica, está profundamente enredado. (WISNIK 1989: 188)

É óbvio que a aparente casualidade sugerida na associação da análise crítico-dialética de Adorno da música dodecafônica com a obra de Mann possui, como é sabido, raízes muitos mais fundas, quiçá, fundamentais para se entender o componente crítico da representação de um compositor de música serial nesta reedição do mito de Fausto. Coube, aliás, ao próprio Mann a tarefa de dar a Adorno o devido mérito na constituição do mundo musical em seu romance: 
Borges, M. J. S. - A música demoníaca de Adrian Leverkühn

Das Manuskript, das er [Adorno] mir damals brachte, und dessen "Einschlägigkeit", dessen frappantes Passen in die Sphäre meines Romans sogleich meine Aufmerksamkeit spannte, hatte im wesentlichen Schönberg, dessen Schule und die Zwölf Ton-Technik zum Gegenstande. Ohne einen Zweifel zu lassen an des Autors Durchdrungenheit von Schönbergs überragender Bedeutung, übt die Schrift doch auch eine scharfblickende, tief schürfende Kritik an dessen System, indem sie in einem äußerst konzisen, ja überschärften, an Nietzsche und mehr noch an Karl Kraus geschulten Stil das Verhängnis erörtert, das die objektiv notwendige konstruktive Erhellung der Musik aus ebenso objektiven Gründen, gleichsam über den Kopf des Künstlers hinweg, in ein Finsteres, Mythologisches zurückschlagen läßt. Was konnte sich besser fügen in meine Welt des "Magischen Quadrats"? (...) Die Darstellung der Reihen-Musik und ihre in Dialog aufgelöste Kritik, wie das XXII. FaustusKapitel sie bietet, gründet sich ganz und gar auf Adorno'sche Analysen, und das tun auch gewisse Bemerkungen über die Tonsprache des späten Beethoven, wie sie schon früh im Buch, in Kretzschmars Expektorationen vorkommen, über das geisterhafte Verhältnis also, welches der Tod stiftet zwischen Genie und Konvenienz.(MANN 1949: 44)

Mais do que a mera apropriação de uma teoria ou o amparo de uma segura e abalizada orientação que tornasse verossímil a música composta pela personagem do romance, a relação de Adorno com a obra de Mann é de afinidade crítica. Como esse último afirma no prosseguimento do trecho acima citado, sua felicidade ao se deparar com o texto do crítico da Escola de Frankfurt se deu porque ele viu ali, plasmadas em forma de análise estético-filosófica, as mesmas angústias e reflexões que o afligiam no conturbado momento histórico alemão no que tangia à arte e à sociedade moderna.

De fato, a aplicação destes conceitos comuns é visível na elaboração feita por Mann do universo musical do romance, muito embora a natureza distinta das motivações contextuais dos dois intelectuais subtraia em alguns aspectos a plenitude dessa afinidade. Adorno escreve, a despeito do altíssimo grau de historicidade que sua formação marxista pressupõe, uma análise da pertinência mimética da música de Schönberg. Por tal razão, o que está em questão para ele é a priori a problematização da relação entre arte e sociedade, conquanto a possibilidade de expandir suas considerações para outras instâncias do conhecimento esteja longe de ser descartada. Mann, por sua vez, tem como principal objetivo a escritura de um romance que, se por um lado, aborda esta mesma questão que envolve arte e sociedade, por outro, com intensidade semelhante, pela própria contingência contextual, enfoca profundamente a questão histórica e o nazismo. Por isso, para dar sentido à tragédia existencial e de valores que 
Borges, M. J. S. - A música demoníaca de Adrian Leverkühn

abarca a concepção estética do compositor Adrian Leverkühn e se expande até a Alemanha hitlerista, Mann precisa elidir, num primeiro momento, da consciência de suas personagens o sentido crítico indissociável da música feita por Schönberg e da análise de Adorno.

No romance, pois, Mann trai a concepção crítica de Schönberg ao tornar seu protagonista um autêntico "continuador" das inovações formais e da postura estéticoutópica de Wagner. Eclipsa-lhe o sentido histórico-mimético que é o fundamento da teoria dodecafônica de Schönberg. Representa, de forma irônica, um artista socialmente alienado afeito unicamente à necessidade estética de elaborar uma música extremamente complexa e jamais escrita. A associação dos elementos formais das composições fictícias de Leverkühn à música ultrahermética de Schönberg se impõe e, com isso, Mann sintetiza em sua personagem a concepção romântica de criação e postura artística. O compositor fictício representa a exacerbação de uma conduta estética desconexa da sociedade, embora sua música, como mimese involuntária de um momento histórico, seja um exemplar semiótico deste mesmo mundo que rejeita:

Die Studierstube des neuen Faust dagegen ist (...) die Hexenküche, in der alle verhängnisvollen Tendenzen der Zeit zu ihrem konzentriertesten Ausdruck gebraut werden. Daß dieser Ausdruck wegen seiner steil kompromißlosen Konsequenz, wegen seiner tragisch zu Ende geführten Härte in der Außenwelt vor allem Befremden und Anstoß erregt, ändert nichts an dieser Einheitsstruktur: die Gedankenwelt, der Werkgehalt, die Werkform, die Werkproblematik Adrian Leverkühns ist die Summa, die Enzyklopädie dessen, was der Geist dieser Zeit - im Guten wie im Bösen - hervorzubringen imstande ist. In der „kleinen Welt“ dieser Studierstube ist die Quintessenz dessen enthalten, was die deutsche Geistigkeit in ihrer „machtgeschützten Innerlichkeit“, in ihrer sozialbedingten In-sich-hinein-Gedrängtheit, In-sichhinein-Geworfenheit (um uns hier, wie es das Thema gebietet, existentialistisch auszudrücken) an „Welt“ besitzt. Diese Studierstube ist der „Große-WeltErsatz" der deutschen Intelligenz der imperialistischen Periode.

(LUKÁCS 1964: 549)

Lukács chama a atenção para a amplitude do sentido histórico que este subjetivismo de Adrian possui e para os indícios catastróficos que ele já supõe. Segundo o crítico húngaro, esta atitude estética da personagem é a manifesta consciência crítica de Mann do desequilíbrio subjetivista que aflige a arte moderna de maneira geral e que traz em si as marcas da sociedade de seu tempo:

Pandaemonium germanicum 15/2010.1, p. 70-90 - www.fflch.usp.br/dlm/alemao/pandaemoniumgermanicum 
Borges, M. J. S. - A música demoníaca de Adrian Leverkühn

Er [Thomas Mann] zeigt, wie das rein Subjektivistische, von jeder Gemeinschaft Entfremdete, jede Gemeinschaft Verachtende einerseits aus dem modernen bürgerlichen Individualismus der imperialistischen Zeit notwendig herauswächst, wie es ebenso notwendig alle alten und neuen Bindungen zur Gesellschaft und im Werk auflöst. (...) Andererseits zeigt Thomas Mann, wie aus dieser selben Lage ununterbrochen die Sehnsucht nach Synthesen, nach Beherrschtsein, nach Ordnung und Organisation entspringt, jedoch ohne jedes reale Fundament im Volksleben, in der gesellschaftlichen Welt, also aus derselben Subjektivität heraus, die die Zersetzung schafft, und eben darum sich selbst auflösend. (LUKÁCS 1964: 555)

Mann expõe assim, na economia do romance, o diálogo inexorável entre criação artística e sociedade. Deixa entrever os riscos desta interiorização anacrônica da arte contemporânea ao vincular, de forma irônica, as tendências "esnobísticas-reacionárias" do subjetivismo romântico de Leverkühn e de sua arte à ideologia política que irá fomentar ou viabilizar o nazi-fascismo do III Reich:

\begin{abstract}
Darum muß diese aus der modernen Zersetzung der Individualität entspringende, aber rein subjektivistisch bleibende Sehnsucht nach Ordnung und Synthese weltanschaulich ununterbrochen jene Tendenzen streifen, die zur Erstarkung der imperialistischen Reaktion, ja zum Faschismus führen. Darin äußert sich das immanente Gerichtetsein der modernen Kunst als formaler Synthese auf die reaktionären Weltanschauungen der Zeit.

Hinter der Leverkühnschen Musik steht also die tiefste Verzweiflung eines wirklichen Künstlers an der Gesellschaftlichkeit der Kunst, ja an der bürgerlichen Gesellschaft unserer Zeit selbst. Alle seine - freilich immanent künstlerisch bleibenden - Durchbruchsversuche steigern nur diese innere Widersprüchlichkeit, diese Selbstauflösung der Kunst infolge ihrer prinzipiellen Lebensferne. Sie führen objektiv zum Absterben der Kunst.
\end{abstract}

(LUKÁCS 1964: 555)

A superação desta atitude subjetiva e alienada só será vislumbrada pelo compositor no fim de seus dias quando então, iluminado por uma trágica e inútil epifania, ele se arrepende do pacto demoníaco feito, dizendo-se enganado pelo enleio romântico que satanizou sua condição artística. Leverkühn, já condenado, tem ciência de que apesar da esterilidade estética que motivara sua música, ela, que lhe fôra viabilizada pelo Diabo e pela sua reclusão quase monástica, é a tradução histórica da decadência social e moral da modernidade. A constatação desta correspondência desperta em Leverkühn a 


\section{Borges, M. J. S. - A música demoníaca de Adrian Leverkühn}

percepção de que, mesmo indiferente às questões sociais de seu tempo, sua música é involuntariamente a materialização da alienação que consome a arte e a sociedade. Sua música é este mesmo mundo doente e condenado à danação que seu alheamento estético esnobara; é a essência da alma que já não lhe pertence e da tentação que o levou à queda:

(...) Es ist die Zeit, wo auf fromme, nüchterne Weis, mit rechten Dingen, kein Werk mehr zu tun und die Kunst unmöglich geworden ist ohne Teufelshilf und höllisch Feuer unter dem Kessel...Ja und ja, liebe Gesellen, daß die Kunst stockt und zu schwer worden ist und Gottes armer Mensch nicht mehr aus und ein weiß in seiner Not, das ist wohl Schuld der Zeit. Lädt aber Einer den Teufel zu Gast, um darüber hinweg und zum Durchbruch zu kommen, der zeiht seine Seel und nimmt die Schuld der Zeit auf den eigenen Hals, daß er verdammt ist. Denn es heißt. Seid nüchtern und wachet! Das aber ist manches Sache nicht, sondern, statt klug zu sorgen, was vonnöten auf Erden, damit es dort besser werde, und besonnen dazu zu tun, daß unter den Menschen solche Ordnung sich herstelle, die dem schönen Werk wieder Lebensgrund und ein redlich Hineinpassen bereiten, läuft wohl der Mensch hinter die Schul und bricht aus in höllische Trunkenheit: so gibt er sein Seel daran und kommt auf den Schindwasen. (MANN 2008: 658)

Este clímax trágico que expõe, às vésperas da danação fatal, a consciência tardia de Leverkühn, é a patente da grande reflexão de Mann sobre o anacronismo da postura "romântica" do artista moderno e do povo alemão e, por conseguinte, também a restauração do caráter crítico da música dodecafônica de Schönberg. Dilui-se, neste derradeiro ato, o que afastava qualitativamente a concepção crítica da música dodecafônica de Mann da de Adorno-Schönberg, ou seja, desfaz-se o estado de inconsciência crítica ao qual o escritor submetia sua personagem para que a reflexão sobre a realidade estético-utópica da arte moderna e sobre a Alemanha nazista pudesse emergir no final dialético do romance:

Entende-se assim o principio de ambivalência, presente em Adorno e Thomas Mann, em que a arte recusa a sociedade existente, mas ao mesmo tempo não pode fugir de mimetizá-la, internalizando as suas contradições mais agudas sob a forma de fracassos e fraturas. (WISNIK 1989: 187)

A música de Leverkühn simboliza, então, obliquamente a confirmação da teoria de Schönberg, da análise de Adorno e, principalmente, da crítica estético-histórica de Mann. Ela é a reiteração da necessidade urgente de se restabelecer, na representação 
Borges, M. J. S. - A música demoníaca de Adrian Leverkühn

artística, um diálogo crítico com as questões sociais mais agudas da contemporaneidade:

Com o doloroso contraponto entre a arte progressista e a história regressiva o romancista quis enfatizar (como diz o crítico marxista Jameson, acertadamente) "não o 'mal' do modernismo [...] mas antes a natureza da tragédia nos tempos modernos: a possessão do homem pelo destino histórico, o intolerável poder da história sobre a vida e sobre a criação artística, a qual não é livre para não refletir aquilo contra o que reage" (WISNIK 1989: 187)

Apesar do teor pessimista desta condição do homem moderno, a moral final do Doktor Faustus, condensada no alumbramento crítico de Leverkühn, deixa ainda uma nesga de esperança para a arte e para a Alemanha. Esta esperança, em perfeita congruência com a luta do escritor contra a unilateralidade romântico-individualista da arte moderna e a favor de uma nova sociedade - de uma nova Alemanha apta a "amar e ser amada"-, alicerçada em valores eminentemente humanísticos, vê, ainda que utopicamente, uma possibilidade de transformação social dos homens baseada na vontade de poder e no equilíbrio espiritual entre as forças subjetivistas e coletivistas presentes no homem e no meio social:

\begin{abstract}
A república ideal seria uma em que todos fossem reis e, apesar das provas abundantes da impensabilidade de aplicação real disso, ela permanecerá como a mais pura idéia de sociedade. Whitman afirmou que defendia a necessidade de uma forte socialização para fortificar a independência da pessoa individual. Seria uma apologia da coletividade vinda de um esteta? Não, apenas uma limitação humana ao individualismo inconsistente de nosso mundo. A afirmação estético-purista do indivíduo é socialmente inviável, para além do domínio artístico, tão bárbara quanto a moderna sociedade de massas. Novalis disse que o todo sempre vive no indivíduo e o indivíduo no todo, portanto é necessário um equilíbrio entre a esfera social e individual, equilíbrio este possível somente através de um peculiar sentimento religioso. Talvez fosse melhor qualificá-lo de místico-carnal para livrá-lo de indesejáveis interpretações colaterais. (MISKOLCI 1997: 69)
\end{abstract}

Neste sentido, é necessário esclarecer que a perspectiva manniana se afasta significativamente das concepções filosóficas desenvolvidas por Adorno quando da análise da música dodecafônica de Schönberg. O crítico da Escola de Frankfurt é taxativo ao propalar a impotência do artista moderno diante da avassaladora e onipresente atuação e interferência qualitativa do sistema capitalista nas mínimas 
Borges, M. J. S. - A música demoníaca de Adrian Leverkühn

instâncias de um processo de criação artística. Segundo ele, referindo-se especificamente à música ocidental, Schönberg, ao propor o dodecafonismo como estágio seguinte na dissolução do sistema tonal, realizou o último e único movimento dialético possível para esta arte. Tal síntese é, pois, a perpetração da paradoxal dialética negativa que se imporá a qualquer ilusão transformadora e progressista que compactue contra o sistema e contras as prerrogativas histórico-materiais do século XX.

De qualquer forma, ao contrário do que possa parecer, esta incompatibilidade prospectiva não invalida a necessidade de superação do subjetivismo-romântico latente no sentido simbólico da danação de Adrian Leverkühn. Afinal, assim como Mann, Adorno também crê que esta imobilidade social e artística imposta pelo sistema capitalista não isenta o homem e o artista moderno de seu compromisso com a reflexão e questionamento crítico destas condições sociais. Para ambos, qualquer outro caminho na arte que não enverede, em sua linguagem e filosofia, na trilha da racionalização crítica das condições histórico-materiais deste tempo recairá, inevitavelmente, numa compreensão enganadora, autodestrutiva e natimorta da realidade social; redundará numa arte inócua que, vendendo fácil o que é a sua própria razão de ser, condena-se, como a pequena sereia do conto de Andersen, a emudecer no hermetismo demoníaco de uma expressão estéril e ininteligível, sem sentido crítico e confirmadora da alienação e reificação deste mundo estranho que lhe restou.

\section{Referências bibliográficas}

AdORnO, T. W. Gesammelte Schriften, Band XII. Frankfurt a. M., Suhrkamp, 2003.

ANDERSEN, Hans Christian. A pequena sereia. In: Contos de Andersen. (Tradução de Guttorm Hanssen). Rio de Janeiro, Paz e Terra, 1978, 83-107.

HAUSER, Arnold. Sozialgeschichte der Kunst und Literatur. München: Beck, 1990.

KIEFER, Bruno. O romantismo na música. In: GUINSBURG, J. (Org.) O romantismo. São Paulo, Perspectiva, 2002, 209-238.

LuKÁCS, Georg. Die Tragödie der modernen Kunst In: Deutsche Literatur in zwei Jahrhunderten. Georg Lukács Werke, Band 7, München, Luchterhand, 1964, 535-582.

Mann, Thomas. Die Entstehung des Doktor Faustus. Roman eines Romans. Frankfurt a.M.: Bermann-Fischer Verlag, 1949. 
Borges, M. J. S. - A música demoníaca de Adrian Leverkühn

. Doktor Faustus. Frankfurt a.M.: S. Fischer, 2008.

Rede, gehalten zur Feier des 80. Geburtstages Friedrich Nietzsches am 15. Oktober 1924. In: Ariadne, Jahrbuch der Nietzsche-Gesellschaft, hg. v. E. Bertram, H. v. Hofmannsthal, Th. Mann, R. Oehler u.a., Verl. der NietzscheGesellschaft, München, 1925.

MisKOLCI, Richard. Eros para presidente - A República Alemã sonhada por Thomas Mann. In: Perspectivas - Revista de Ciências Sociais. São Paulo, UNESP, 1997, V.20/21, 67-76.

NiETZsCHE, F. Nietzsche's Werke, VIII. Leipzig, C. G., Naumann Verlag, 1906.

Rosenfeld, Anatol. As causas psicológicas do Nazismo In: Texto/Contexto II. - São Paulo: Perspectiva, 1993, 171-188. (Debates; vol.254)

Aspectos do romantismo alemão In: Texto/Contexto I. - São Paulo: Perspectiva, 1996, 147-172. (Debates; vol.7)

. Beethoven e o romantismo In: Texto/Contexto I. - São Paulo: Perspectiva, 1996, 275-282. (Debates; vol.254)

. Nietzsche e o irracionalismo In: Texto/Contexto I. - São Paulo: Perspectiva, 1996, 65-76. (Debates; vol.254)

. Thomas Mann. - São Paulo: Perspectiva, 1994. (Debates; vol.259)

. Thomas Mann: Apolo, Hermes, Dioniso In: Texto/Contexto I. - São Paulo: Perspectiva, 1996, 201-224. (Debates; vol.7)

WISNIK, José Miguel. O som e o sentido: uma outra história das músicas. São Paulo, Companhia das Letras, 1989. 